\title{
Meurtrières (extraits)
}

\author{
Louise Cotnoir
}

\section{Meurtrières (extraits)}

This sequence of paired paragraphs, the first in the $3 r d$ person, the second in the 1st person, re-enact the double play of its title, "murderesses" and "loopholes." Stuck in the alternatives of murder or embrace ("love kills women"), murder or madness, she is a subterranean force, a voice at ease for too long, the neuter of gender and role saying neither yes nor no, elaborating her rage, I weighs, analyzes, attacks words, recognizes the intolerable, stays there in it saying what it is. "The world worries me, foolishly," Ominously.

Elle aime les jours où ses seins s'alourdissent. C'est une façon de peser sur le réel. Elle porte son corps come une verité, sa seduction. Quelque chose de l'excès sans la douleur.

Je suis celle qui est de trop. Je crache mon nom avec le sang. 
Meurtrières (extraits) · 123

Avec une vigilance intime, elle a peur d'être une femme qui pense. Elle se gratte la peau jusqu'à l'arracher. Elle se mord les lèvres. Comment se déprendre de la fascination? Le meurtre ou l'étreinte. Sa voix au repos depuis si longtemps. Elle a perdu la tonalité.

L'amour tue les femmes. Je traverse l'abîme sur un fil de sang. 
Certains gestes extravagants. Dire non. Elle sait les conduites mauvaises, excentriques. Elle ne se résout pas au silence. Une force souterraine. Peut-être un volcan. L'éruption formidable quand elle ouvre la bouche sur le sexe muselé

Le cerné de mes yeux ne me dit rien qui vaille. J'envisage la fureur avant la mort, les vacances. 
Meurtrières (extraits) $\cdot 125$

Cynique et joyeuse devant le spectable effrayant du monde. Elle ne dit ni oui ni non. Pour ne pas manquer d'air. Le neutre du genre et du rôle, là s'écrit la trahison. Toutes des folles.

Je m'en prends aux mots et je gifle. Diaboliquement vivace. 


\section{6 - Tessera}

Activité fiévreuse. Elle détruit certains mots qui lui portent atteinte. La coercition se déplace. Errer est une façon de se soustraire à la répétition prolongée de la mort. Nuit aprés nuit, elle s'étend sur sa rage. Abandonnée, intacte.

Je pèse le mot femme avec les fruits. J'y trouve mon compte et une raison. 
Meurtrières (extraits) $\cdot 127$

Les faits divers lui font plier l'échine. Bouc émissaire. Comment devenir barbare parmi les Barbares? Elle veut l'indécence et l'excuse de la folie. Le désespoir concret. L'heure n'est plus au doute.

Dies irae. J'écoute l'opéra de la mort. Je me plais à imaginer la mer et ses ombres. 
Défigurée de passion. Il s'agit bien de cela. Noire et charmante dans la torsion tragique de ses bras. Elle s'excuse de ne pas savoir vivre. Le monde lui échappe, sensuel et inquiétant.

Dès le réveil, je reste là. Rompue à la courbe de l'intolérable. 
Meurtrières (extraits) $\cdot 129$

Elle a une mine d'épouvante. Le meurtre plutôt que la folie. A quoi pense-t-elle en souhaitant la nuit? Elle marche au bord de sa peur, du précipice. L'amour bascule. Avec les pervenches qui s'inclinent sous la première neige.

Le monde m'inquiète, follement. 